\title{
Transplacental Exposure to AZT Induces Adverse Neurochemical and Behavioral Effects in a Mouse Model: Protection by L-Acetylcarnitine
}

\author{
Anna Rita Zuena ${ }^{19}$, Chiara Giuli ${ }^{19}$, Aldina Venerosi Pesciolini' ${ }^{2}$, Antonella Tramutola ${ }^{1}$, Maria \\ Antonietta Ajmone-Cat ${ }^{2}$, Carlo Cinque ${ }^{1}$, Giovanni Sebastiano Alemà ${ }^{1}$, Angela Giovine', \\ Gianfranco Peluso ${ }^{5}$, Luisa Minghetti ${ }^{3}$, Raffaella Nicolai ${ }^{4}$, Gemma Calamandrei ${ }^{2 *}$, Paola Casolini ${ }^{1}$
}

1 Department of Physiology and Pharmacology "Vittorio Erspamer", I Faculty of Medicine, Sapienza University of Rome, Rome, Italy, 2 Section of Neurotoxicology \& Neuroendocrinology, Department of Cell Biology and Neurosciences, Istituto Superiore di Sanità, Rome, Italy, 3 Section of Experimental Neurology, Department of Cell Biology and Neurosciences, Istituto Superiore di Sanità, Rome, Italy, 4 Therapeutic Area Life Cycle Management, Corporate R\&D Sigma-Tau S.p.A., Pomezia, Rome, Italy, 5 Institute of Biochemistry of Proteins, CNR, Naples, Italy

\begin{abstract}
Maternal-fetal HIV-1 transmission can be prevented by administration of AZT, alone or in combination with other antiretroviral drugs to pregnant HIV-1-infected women and their newborns. In spite of the benefits deriving from this lifesaving prophylactic therapy, there is still considerable uncertainty on the potential long-term adverse effects of antiretroviral drugs on exposed children. Clinical and experimental studies have consistently shown the occurrence of mitochondrial dysfunction and increased oxidative stress following prenatal treatment with antiretroviral drugs, and clinical evidence suggests that the developing brain is one of the targets of the toxic action of these compounds possibly resulting in behavioral problems. We intended to verify the effects on brain and behavior of mice exposed during gestation to AZT, the backbone of antiretroviral therapy during human pregnancy. We hypothesized that glutamate, a neurotransmitter involved in excitotoxicity and behavioral plasticity, could be one of the major actors in AZT-induced neurochemical and behavioral alterations. We also assessed the antioxidant and neuroprotective effect of L-acetylcarnitine, a compound that improves mitochondrial function and is successfully used to treat antiretroviral-induced polyneuropathy in HIV-1 patients. We found that transplacental exposure to AZT given per os to pregnant mice from day 10 of pregnancy to delivery impaired in the adult offspring spatial learning and memory, enhanced corticosterone release in response to acute stress, increased brain oxidative stress also at birth and markedly reduced expression of mGluR1 and mGluR5 subtypes and GluR1 subunit of AMPA receptors in the hippocampus. Notably, administration during the entire pregnancy of L-acetylcarnitine was effective in preventing/ameliorating the neurochemical, neuroendocrine and behavioral adverse effects induced by AZT in the offspring. The present preclinical findings provide a mechanistic hypothesis for the neurobehavioral effects of AZT and strongly suggest that preventive administration of L-acetylcarnitine might be effective in reducing the neurological sideeffects of antiretroviral therapy in fetus/newborn.
\end{abstract}

Citation: Zuena AR, Giuli C, Venerosi Pesciolini A, Tramutola A, Ajmone-Cat MA, et al. (2013) Transplacental Exposure to AZT Induces Adverse Neurochemical and Behavioral Effects in a Mouse Model: Protection by L-Acetylcarnitine. PLoS ONE 8(2): e55753. doi:10.1371/journal.pone.0055753

Editor: Michel Baudry, Western University of Health Sciences, United States of America

Received September 12, 2012; Accepted December 31, 2012; Published February 7, 2013

Copyright: (c) 2013 Zuena et al. This is an open-access article distributed under the terms of the Creative Commons Attribution License, which permits unrestricted use, distribution, and reproduction in any medium, provided the original author and source are credited.

Funding: The study was supported by funds to P.C. from University of Rome (faculty project 2009 prot. C26F09YEXM) and partly sponsored by Sigma-Tau I.F.R. $\mathrm{SpA}$ (Rome) (D.S./2007/C.R./n ${ }^{\circ}$ ). Raffaella Niccolai is an employee of the SIGMA TAU and participated in manuscript preparation and data analysis as an expert of acetylcarnitine. The funders had no role in study design, data collection and analysis, decision to publish, or preparation of the manuscript.

Competing Interests: Doctor Raffaella Nicolai is employed at Sigma-tau S.p.A. as Medical Research Senior Advisor; Raffaella Nicolai and Paola Casolini have been designated among inventors in the following European patent application: 11137170.3-2112 "Compound useful for preventing cognitive deficit disorders in a new born from HIV-seropositive pregnant female who is on treatment with azidothymidine". Part of this study has been financially supported by Sigma Tau-IFR S.p.A., Italy that has synthesized and provided L-acetylcarnitine. Sigma-tau is an Italian pharmaceutical company involved in research on carnitine system which produces and sells carnitine as drugs. This does not alter the authors' adherence to all the PLOS ONE policies on sharing data and materials. There are no other competing interests to declare.

* E-mail: gemma.calamandrei@iss.it

9 These authors contributed equally to this work.

\section{Introduction}

Since 1994, effective reduction in maternal-fetal HIV-1 transmission has been achieved by administration of antiretroviral (ARV) agents to HIV-1-infected women during pregnancy and to their newborns during early neonatal period [1]. The benefits deriving from the introduction of prophylactic ARV therapy are unquestionable but there is still considerable uncertainty on the potential long-term adverse effects of ARV agents on exposed children, in particular as for nucleoside reverse transcriptase inhibitors (NRTIs) [2]. In US and Europe, standard protocols of care for pregnant seropositive women and their newborns always include the NRTI zidovudine (AZT), alone or in combination with another NRTI, a non-NRTI or a protease inhibitor [3,4].

Toxic effects of chronic treatment with AZT-based therapies have been widely documented in HIV-1 positive adults, including liver failure, lactic acidosis, myopathy, and neuropathy. These 
adverse effects have been mainly related to the ability of NRTIs, secondary to their antiviral action [5], to interfere with mitochondrial function in different target organs [6-8]. Specifically AZT induces alterations in mitochondrial structure and function by (a) direct inhibition of mtDNA replication and repair via inhibition of mtDNA polymerase $\gamma$; (b) alterations in cellular metabolism affecting oxidative phosphorylation enzyme activity and generation of reactive oxygen species; (c) mutations via incorporation of the NRTI into mtDNA and replication blockage $[9,10]$.

Results from clinical and cohort studies in offspring of women exposed to NRTIs during pregnancy, though excluding major adverse effects [4], have clearly shown the occurrence of subclinical mitochondrial dysfunction [11,12], whose long-term repercussion on high-requiring energy tissues, such as the heart and the brain, is still a matter of concern. In a study carried out in a small number of infants born to HIV-1-positive women, quantification of mtDNA in cord blood evidenced mitochondrial damage and mtDNA depletion in NRTI-exposed infants when compared to unexposed infants [13]. A prospective study carried out in a large cohort of non-infected children within the French Pediatric Cohort reported the occurrence of symptoms compatible with mitochondrial dysfunction in a significant proportion of NRTI-exposed infants [14]. Such symptoms were primarily neurologic and included cognitive delay, motor disturbances, white-matter alteration in Magnetic Resonance Imaging and increased risk to develop febrile seizures, associated to deficits in one of the mitochondrial respiratory chain complexes [14-16]. Since AZT is central to highly active ARV therapy for reducing mother-to-child transmission of HIV-1 [4,17], it is important to determine the nature and magnitude of the long-term effects of in utero AZT exposure as well as the mechanisms underlying the toxicities of this compound. However, in epidemiological studies the methodological issues related the potential effects of antiretroviral medications on neurobehavioral development are very complex, given the numerous co-morbidity factors that may influence neurobehavioral outcome in this specific group of children. These factors include, among the others, in utero exposure to maternal pro-inflammatory cytokines released during HIV infection, prenatal exposure to drug of abuse, family disruption, mental health problems in parents and birth complications [18]. Animal models represent a useful tool to overcome the methodological and ethical constraints implicated in human studies, and to investigate the etiology of antiretroviral drugs' toxicities in the absence of other confounding factors. A number of animal studies have been devoted to address this issue. These studies have clearly shown that developmental exposure to AZT produces both early and delayed behavioral changes in offspring. The behavioral endpoints affected by transplacental exposure to AZT include sensor and motor maturation, learning abilities, social/aggressive behavior, exploration levels [19-30]. Knowledge of the neural bases of behavioral AZT toxicity is so far very limited, but it has been clearly shown that at doses comparable to those used in clinical practice, AZT acts as a mitochondrial toxin in rodents and non-human primates [31-36]. Extensive evidence links dysfunctions of mitochondrial energy supply and the resulting oxidative stress to excessive release of glutamate [37] the major excitatory neurotransmitter in the mammalian central nervous system (CNS). By acting on ionotropic (iGlu) and metabotropic (mGlu) receptors, glutamate has a wide array of effects, ranging from modulation of learning and memory capacities [38-40], neuroendocrine secretion of glucocorticoids [41] and regulation of synaptic transmission and plasticity in the CNS $[42,43]$. On these bases, we hypothesize that the behavioral alterations found in rodents exposed to AZT in utero are linked to oxidative stress resulting from AZT mitochondrial toxicity through the involvement of the glutamate system.

In order to assess this hypothesis we first evaluated in adult mice exposed in utero to AZT at clinical relevant doses spatial learning capacities, corticosterone response to acute stress, hippocampal glutamate receptors expression and oxidative stress, the latter by means of isoprostane and oxidized proteins level measurement. Furthermore, considering the implication of early oxidative stress induced by AZT in development of delayed neurobehavioral alterations, we evaluated whether the administration during pregnancy of a neuroprotective agent such as L-acetylcarnitine (LAC), capable of protecting mitochondria from damage induced by different noxa, was able to protect the transplacental AZTexposed offspring from the CNS toxicity of this drug and, consequently, from the resulting behavioral impairment.

LAC, the acetyl ester of L-carnitine is a naturally occurring endogenous compound in all mammalian species present in relatively high levels in the brain, in particular in hypothalamus and hippocampus. When systemically administered, LAC readily crosses the blood-brain barrier influencing brain metabolism. LAC neuroprotective effects rely on improved mitochondrial energetic function, potentiation of antioxidant activities, stabilization of membranes, modulation of protein and gene expression [44].

Clinical studies have shown that treatment with LAC improved NRTI-induced polyneuropathy symptoms including pain, paraesthesia and numbness in HIV-1-positive patients [45-48]. However, the potential efficacy of LAG in protecting from the side effects of the prophylactic ARV therapy in pregnancy has never been studied so far.

\section{Materials and Methods}

\section{Ethics Statement}

This study was carried out in accordance with the Italian Animal Welfare legislation (art 4 and 5 of D.L. 116/92) that implemented the European Committee Council 106 Directive (86/609/EEC). The Italian Ministry of Health specifically approved the protocol of this study on $12 / 21 / 2009$, Authorization n ${ }^{\circ} 224 / 2009-b$ to G.C.

\section{Animals and housing conditions}

Adult male $(n=30)$ and virgin female $(n=60)$ mice of the out bred Swiss-derived strain (CD-1) were purchased from Charles River. Upon arrival at the laboratory, the animals were housed in an air-conditioned room (temperature $21 \pm 1^{\circ} \mathrm{C}$, relative humidity $55 \pm 5 \%$ ) with a reversed 12:12 light cycle (light on at $19.00 \mathrm{~h}$, light off at $07.00 \mathrm{~h}$ ). Water and food were available ad libitum. Females were group-housed (4 per cage) for 7 days to coordinate their estral cycle. After that, pairs of female mice were housed with a single sexually experienced male mouse. Females were daily inspected for the presence of a vaginal plug (gestational day 0; GD0) and then individually housed in Plexiglas cages $(33 \times 13 \times 14 \mathrm{~cm})$. Pregnancy rate was about $75 \%$. The litters were culled at birth to four females and four males, to maintain adequate litter composition. Only male offsprings were used in this study.

\section{Experimental procedures}

The experimental design of this study is depicted in Fig. 1. AZT was purchased from Sigma-Aldrich and LAC was provided by Sigma-Tau S.p.A. AZT was dissolved in bidistilled water and LAC in saline.

Following finding of the vaginal plugs 45 females were randomly assigned to one of the two subcutaneous (s.c.) treatments with either $\mathrm{LAC}(100 \mathrm{mg} / \mathrm{kg}$, in a volume of $1.25 \mathrm{ml} / \mathrm{kg})$ or 


\section{EXPERIMENTAL DESIGN}

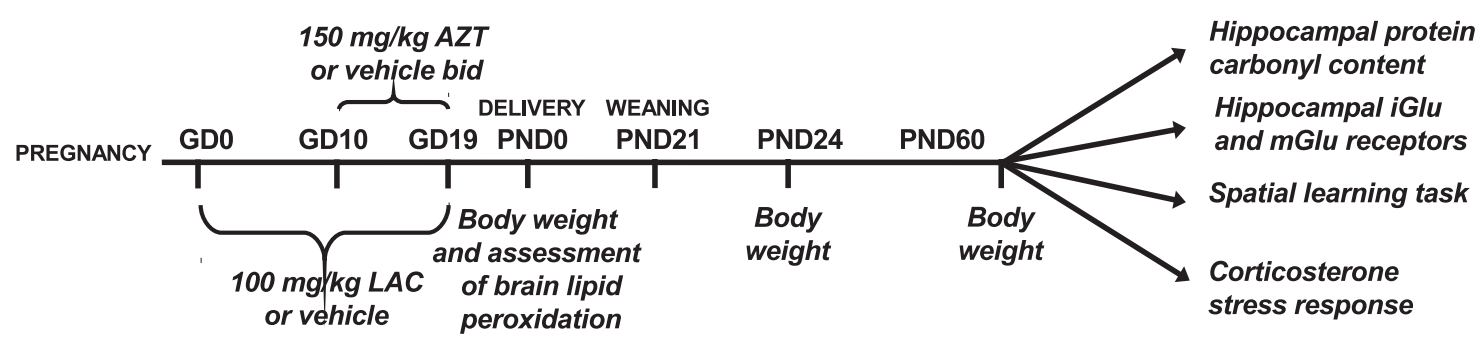

Figure 1. Experimental design of the study. doi:10.1371/journal.pone.0055753.g001

vehicle (saline, same volume as LAC) that were administered daily from GD0 to the day of delivery. Starting on GD10, pregnant mice in each vehicle and LAC group were also administered by oral gavage (p.os) with either water $(3.3 \mathrm{ml} / \mathrm{kg})$ or AZT $(150 \mathrm{mg} /$ $\mathrm{kg}$, same volume) in the morning and evening till the day of delivery. The resulting treatment groups were as follows: Control (saline s.c.+water p.os), LAG (LAC s.c.+water p.os), AZT (saline s.c.+AZT p.os) and AZT+LAC (AZT p.os.+LAC s.c.)

The AZT dose administered has been selected after multi-dose studies and taking into account the results of other groups' and ours studies in rodents, which identified doses producing behavioral effects and/or mitochondrial dysfunction in absence of significant reproductive or morphological effects in the mother and offspring $[22,29]$.

In order to measure the AZT levels in blood and brain, blood was withdrawn from the orbital plexus after delivery in five mothers of AZT group at the end of pregnancy, in a period between 8 and 12 hours after the last AZT treatment. Four pups from each of the same litters were sacrificed at birth, and their plasma and brain hemispheres collected and pooled $(n=5)$.

Females' body weight was monitored daily during pregnancy. Proportion of term pregnancies, gestation length, litter size, sex ratio and neonatal mortality were also measured to exclude potential effects of the treatment on reproductive performances. The day of birth was defined as postnatal day 0 (PND0). At this age, before litter culling, eight pups from each treatment group were sacrificed for F2-isoprostane measurement in the total brain homogenate. Weaning took place at 21 days of age (PND21) and male offspring of each group housed in two per cage. They were maintained under controlled environmental conditions until 2 months of age (PND60) when they were assigned to water maze spatial learning test, plasma corticosterone assay, protein oxidation and glutamate receptor analysis. Body weights were recorded at birth (PND0), after weaning (PND24) and before performance of the spatial learning task (PND60).

\section{Determination of AZT Concentrations in Plasma and Brain Homogenate}

Plasma and brain homogenate samples were analyzed separately using spiked standards in blank plasma and brain homogenate. Commercial available AZT (Sigma-Aldrich) was used as internal standard. For plasma, $100 \mu \mathrm{l}$ samples were spiked with $100 \mathrm{ng}$ of internal standard. The samples were subjected to liquid-liquid extraction using 8 parts of ethyl acetate for 1 part of sample and vortexed vigorously for $5 \mathrm{~min}$. The mixture was centrifuged at $14,000 \mathrm{rpm}$ at room temperature for $10 \mathrm{~min}$. The supernatant was transferred to clean glass tubes, dried under a flow of liquid nitrogen, and reconstituted in $100 \mu \mathrm{l}$ of mobile phase, and $30 \mu \mathrm{l}$ was injected onto the HPLC column. Whole brain was homogenized in 3 volumes of $5 \%$ bovine serum albumin in PBS using a Dounce homogenizer ( 7 ml; Kontes Glass); $500 \mu \mathrm{l}$ of brain homogenate was spiked with $50 \mathrm{ng}$ of internal standard, and sample preparation was similar to that of plasma. The mobile phase for AZT analysis consisted of buffer $(50 \mathrm{mM}$ ammonium phosphate, $50 \mathrm{mM}$ sodium citrate buffer, and $10 \mathrm{ppm}$ sodium azide, $\mathrm{pH} 6.5)$ and methanol (82:18) at a flow rate of $0.2 \mathrm{ml} / \mathrm{min}$, and UV absorbance was measured at $266 \mathrm{~nm}$. The plasma and brain concentrations are reported as nanograms per milliliter and nanograms per gram of brain tissue, respectively.

\section{HPLC Analysis}

AZT determination was performed by HPLC analysis using a Hypersil-BDS column (C-18, $2.1 \mathrm{~mm} \times 150 \mathrm{~mm}, 5 \mu \mathrm{M}$; Thermo Electron Corporation) maintained at $40^{\circ} \mathrm{C}$ using a Shimadzu column oven (CTO-10Avp). The HPLC system consisted of a Shimadzu pump (LC-10ATvp), flow control valve (FCV-10ALvp), degasser (DGU-20A5), auto injector (SIL-10ADvp), system controller (SCL-10Avp), and detector (SPD-10Avp).

\section{F2-isoprostane measurement}

On PND0 the levels of the $\mathrm{F}_{2}$-isoprostane $\left(\mathrm{F}_{2}\right.$-IsoP) were measured in brain homogenates, as previously described [49]. Briefly, brains were weighed and homogenized in $50 \mathrm{mM}$ Tris buffer, pH $7.5(1 \mathrm{mg} / 0.1 \mathrm{ml})$, containing the anti-oxidant $10 \mu \mathrm{M}$ BHT to block spontaneous oxidation. Homogenates were vigorously vortexed and incubated for $5 \mathrm{~min}$ on ice before centrifuging at $14,000 \mathrm{rpm}$ for $45 \mathrm{~min}$ at $4^{\circ} \mathrm{C}$. Supernatants were collected and stored at $-80^{\circ} \mathrm{C}$ until required. $15-\mathrm{F}_{2 \mathrm{t}}-\mathrm{IsoP}$, the major member of $\mathrm{F}_{2}$-IsoP family, was measured by a specific enzyme immunoassay (Cayman Chemical), according to the manufacturer's instructions. Detection limit was $2 \mathrm{pg} / \mathrm{ml}$; anti$15-\mathrm{F}_{2 \mathrm{t}}$-IsoP antibody cross-reactivity with other iso-prostaglandins was less than $0.15 \%$.

\section{Detection of Oxidized Proteins}

Protein oxidation was measured in the same homogenates utilized for western blot of glutamate receptors in 2-month-old mice. Oxidized protein was detected by using an oxidized protein detection kit (OxyBlot, Chemicon International). The OxyBlot provides reagents for sensitive immunodetection of carbonyl groups, which is a hallmark of the oxidation status of proteins. The procedure was performed according to manufacturer's recommendation. Briefly, $30 \mu \mathrm{g}$ of hippocampal homogenates were derivatized with or without 2,4-dinitrophenylhydrazine (DNPH) and samples loaded onto a 12\% SDS-PAGE gel. After separation, proteins were electrotransferred to a nitrocellulose 
membrane and incubated with a primary antibody against the derivatized carbonyl groups followed by incubation with a horseradish peroxidase-conjugate goat anti-rabbit antibody. The oxidized proteins were visualized by using an enhanced chemiluminescence system (Amersham Biosciences). The relative optical densities were quantified using the NIH ImageJ medical imaging software. No immunoreactivity was detected in the non-DNPH derivatized brain homogenates.

\section{Water Maze procedure}

On PND60 mice from each treatment group were tested in the Morris water maze for their spatial learning ability, applying a one-day protocol that has been successfully applied to different strains of mice [50]. The apparatus consisted of a circular pool (diameter $110 \mathrm{~cm}$, height $60 \mathrm{~cm}$ ) located in a test room with white walls with several cues on them. The pool, with its inner surface painted black, was filled to a depth of $40 \mathrm{~cm}$ with water (maintained at $25 \pm 1^{\circ} \mathrm{C}$ ), covering an invisible (black) $10-\mathrm{cm}$ square platform. The platform was located approximately $0.5 \mathrm{~cm}$ below the surface of the water. The pool was virtually divided into 4 quadrants (North, South, East, or West) and the platform placed at a fixed position in the center of the North quadrant. A singleday training procedure was carried out, and each subject underwent four four-trial sessions of training, with each session separated by $30 \mathrm{~min}$. On each trial, the subject was gently released in the water with its head facing the pool wall from one of quadrants. The order of the starting quadrant was changed in each session and trial. A maximum of $60 \mathrm{sec}$ was allowed, during which the mouse had to find the platform, climb onto it and allowed to remain there for $10 \mathrm{sec}$. If the animal did not find the platform, it was gently guided with a grid and allowed to stay for 10 sec.

A video camera above the center of the pool was connected to a computerized tracking system that recorded and analyzed animal behavior (San Diego Instruments). The time of escape onto the platform and the swimming speed were measured. After the last trial of the last session of training, animals were submitted to a single $60 \mathrm{sec}$ "probe trial" in which the platform was removed from the pool. The animal started the probe trial in the south quadrant and the time that it swam through the north quadrant, where the platform had been previously located, provided a measure of learning accuracy in recalling the former position of the platform. A session with a visible platform was performed at the end of the learning task to assess the swimming speed of the different groups of animals.

\section{Corticosterone secretion after acute restraint stress}

A second group of mice from each treatment group was used for assessment of plasma corticosterone levels in basal conditions and following $15 \mathrm{~min}$ of acute restraint stress. The procedure was performed in the animal facility at 9:00 AM. Restraint stress was performed as follows: the mouse was removed from its cage and placed in an adjustable Plexiglas restraint device for 15 min under a very bright light. Blood samples were collected from the tail tip in heparinized capillary tubes at the beginning (basal value) and at the end of the restraint procedure (stress value). At the end of the procedure the mice were immediately returned to their cages. Blood samples were centrifuged at $1900 \times \mathrm{g}$ at $4^{\circ} \mathrm{C}$ for $20 \mathrm{~min}$; plasma was removed and kept frozen at $-20^{\circ} \mathrm{C}$ until assay. Plasma corticosterone concentrations were determined by radioimmunoassay (MP Biomedicals). The cross-reactivity of the polyclonal corticosterone-antisera with respective related substances was negligible. The inter- and intra-assay coefficients of variance were
$7 \%$ and $4 \%$, respectively, with a detection limit of $0.01 \mu \mathrm{g} /$ $100 \mathrm{ml}$.

\section{Western blot analysis}

A third set of mice was sacrificed on PND60 to assess expression of iGlu and mGlu receptors. For the iGlu receptors we assessed AMPA Glu1 and Glu2 subunit, and NMDA NR1 subunit. For the mGlu receptors we measured both group I mGluR1 and mGluR5 subtypes and group II mGlu2/3 subtypes. Mice were killed by decapitation and brains rapidly removed; hippocampi were dissected and stored at $-80^{\circ} \mathrm{C}$. On the day of the experiment, tissue was homogenized at $4^{\circ} \mathrm{C}$ with a polytron in $500 \mu \mathrm{l}$ of $100 \mathrm{mM}$ Tris buffer, containing phenylmethylsulfonyl fluoride $1 \mathrm{mM}$, leupeptin $10 \mu \mathrm{g} / \mathrm{ml}$ and aprotinin $10 \mu \mathrm{g} / \mathrm{ml} \mathrm{pH} \mathrm{7.2.}$ Protein concentrations were determined using the Bradford protein assay. Thirty micrograms of protein were re-suspended in sodium dodecyl sulfate (SDS)-bromophenol blue loading buffer with $0.5 \mathrm{M}$ dithiothreitol. The samples were separated on $8 \%$ SDS-polyacrylamide gels (Amersham Bioscience) and after electrophoresis (Mini-PROTEAN 3 System, Bio-Rad), the proteins were transferred to nitrocellulose membranes (Amersham Bioscience) using a system of mini transblot cell (BioRad) overnight. After transfer, blots were incubated in a solution (blocking solution) containing Tris-buffered saline (TBS), 10\% (w/v) Tween-20, 1\% (w/v) non-fat milk and 1\%(w/v) bovine serum albumin. Subsequently, blots were incubated overnight with rabbit anti-mGluRla (1:1000), anti-mGluR5 (1:1000), anti-mGluR2/3 (1:1000), anti-NR1 (1:1000), mouse antiGlul (1:500) (Upstate Biotechnology) and mouse antiGlu2 (1:500; Chemicon International) in blocking solution at $4^{\circ} \mathrm{C}$. After incubation with the primary antibody, the blots were incubated with horseradish peroxidase-conjugated goat anti-rabbit or anti-mouse antibodies (1:5000; Amersham Bioscience) for $1 \mathrm{~h}$ at room temperature $\left(21^{\circ} \mathrm{C} \pm 2\right)$. To ensure that each lane was loaded with an equivalent amount of protein, the blots were probed with an anti-actin serum (1:1000; Sigma) overnight at $4^{\circ} \mathrm{C}$. Subsequently, blots were incubated with horseradish peroxidase-conjugated goat antimouse antibodies (1:5000; Amersham Bioscience) for $1 \mathrm{~h}$ at room temperature. Immunoreactive bands were visualized with an enhanced chemiluminescence system (Amersham Biosciences). After immunoblotting, digitized images of bands immunoreactive for target (mGluR1, mGluR5, mGluR2/3, NR1 or Glu1) and control (actin) molecules were acquired and the area of immunoreactivity corresponding to each band was measured using the NIH ImageJ medical imaging software. A ratio of target to actin was then determined, and these values were compared for statistical significance.

\section{Statistical analysis}

Body weight data were analyzed separately for each age point by one-way ANOVA. Latencies to reach the platform in the Morris water maze were analyzed by three-way ANOVA for repeated measures (treatment $\times$ trial $\times$ session with repeated measures on trials and sessions). Each litter in each final treatment group contributed with a single subject to spatial learning task, corticosterone assessment and measurement of glutamate receptors/protein carbonyl content. The ANOVA analyses were always followed by Fisher's LSD post-hoc comparisons. Probe trial, swimming speed, plasma corticosterone concentrations and immunoblotting data were analyzed by Student's t-test. The level of significance was set at $\mathrm{p}<0.05$. 


\section{Results}

AZT administered during gestation reaches the brain of fetuses

In female mice after delivery, mean AZT plasma concentration was $8.6 \pm 1.0 \mathrm{ng} / \mathrm{ml}$, a value comparable to that found in women treated during pregnancy following clinical protocols [51]. Plasma concentration of AZT in pups was undetectable, but significant AZT levels were found in the brain $(70.2 \pm 6.1 \mathrm{ng} / \mathrm{mg}$ of brain tissue), indicating the transplacental passage of AZT to the brain of fetuses (AZT vs Control, p $<0.05$ Fisher's LSD post-hoc).

\section{AZT induced decrease of body weight at birth is not prevented by LAC}

Proportion of term pregnancies, gestation length, litter size, sex ratio and neonatal mortality was not affected by prenatal treatment with AZT or LAC. The mean body weight of the offspring at different ages is shown in Table 1. At birth (PND0) AZT treatment significantly decreased body weight (main treatment effect $\mathrm{F}_{3,36}=11.58, \mathrm{p}<0.05$; AZT vs Control, $\mathrm{p}<0.05$ Fisher's LSD post-hoc), an effect that was not prevented by administration of LAC in the AZT+LAC group (AZT+LAC vs Control, $\mathrm{p}<0.05$ Fisher's LSD post-hoc). LAC per se did not modify pups' body weight at birth, but increased it on PND24 (LAC vs all other groups, $\mathrm{p}<0.05$ Fisher's LSD post-hoc). At PND60, mean body weight was comparable in the four experimental groups.

\section{AZT- induced impairment of spatial learning and memory is counteracted by LAC treatment}

Figure $2 \mathrm{~A}$ shows the latencies to reach the hidden platform throughout the four sessions of the Morris water maze. ANOVA for repeated measures evidenced a significant main effect of the treatment received $\left(\mathrm{F}_{3,26}=5.95, \mathrm{p}<0.05\right)$ and a significant three way interaction treatment $\times$ session $\times$ trial $\left(\mathrm{F}_{3,27}=1.89, \mathrm{p}<0.05\right)$. Post-hoc analysis showed that subjects receiving prenatal AZT treatment displayed a significant increase in escape latency in comparison to the Control group in all the four sessions. The AZT+LAC group had escape latencies comparable to the Control group and significantly different from those of the AZT group in the $3^{\text {rd }}$ and $4^{\text {th }}$ session, suggesting that pre-treatment with LAC significantly improved the AZT-induced acquisition deficit. Finally, LAC treatment alone did not modify learning abilities.

During the probe trial (Fig. 2B) AZT subjects spent significantly lower time than Control mice in the quadrant where the hidden platform was located during the acquisition trials $(\mathrm{t}=-2.05$, $\mathrm{p}<0.05)$, indicating that they were impaired in recalling the

Table 1. Effect of transplacental exposure to AZT and LAC on body weight recorded at different ages in male offspring.

\begin{tabular}{lllll}
\hline & Control & AZT & LAC & AZT+LAC \\
\hline PND0 & $1.83 \pm 0.04$ & $1.63 \pm 0.03^{*}$ & $1.89 \pm 0.06$ & $1.57 \pm 0.05^{*}$ \\
PND24 & $15.01 \pm 0.81$ & $14.49 \pm 0.68$ & $17.04 \pm 0.77 \#$ & $14.43 \pm 0.51$ \\
PND60 & $38.69 \pm 1.17$ & $37.04 \pm 1.75$ & $39.71 \pm 1.13$ & $37.46 \pm 1.24$ \\
\hline
\end{tabular}

AZT treatment affected body weight at birth irrespectively of LAC

administration, but this effect disappeared by PND 24. LAC treated mice was generally heavier than Control group. (Fisher's LSD post-hoc after one way ANOVA:

${ }^{*} p<0.05$ vs Control;

${ }^{\#} p<0.05$ vs all other groups). Values are means \pm S.E.M $(n=9-11$ mice per group).

doi:10.1371/journal.pone.0055753.t001 former position of the platform. Notably, performances of AZT+LAC mice in probe trial did not differ from those of Controls.

No treatment-induced difference was recorded in the swimming speed of the different groups of mice (Fig. 2C).

\section{LAC treatment protects from AZT-induced enhancement of stress response}

In basal conditions, no significant differences were found in plasma corticosterone levels between groups (Controls $=4.10 \pm 0.41 \mu \mathrm{g} / \mathrm{dl} ; \quad \mathrm{AZT}=3.47 \pm 0.37 \mu \mathrm{g} / \mathrm{dl}$; $\mathrm{LAC}=3.45 \pm 0.65 \mu \mathrm{g} / \mathrm{dl} ; \quad \mathrm{AZT}+\mathrm{LAC}=3.34 \pm 0.29 \mu \mathrm{g} / \mathrm{dl}) . \quad$ Student's $t$-test of plasma corticosterone stress response, calculated as differences (delta) between restraint stress values and basal values, revealed that mice in the AZT group had higher plasma corticosterone concentration in respect to the Control group $(\mathrm{t}=2.76, \mathrm{p}<0.05)$. Of note, the AZT+LAC animals showed levels of corticosterone similar to the control mice suggesting that the prenatal treatment with LAC was able to protect the development of hypothalamus pituitary adrenal (HPA) axis from the effects of AZT (Fig. 3).

\section{Reduced expression of hippocampal metabotropic and ionotropic Glu receptors caused by AZT is counteracted by LAC treatment}

The AZT prenatal treatment caused a significant reduction of mGlula receptor expression in respect to Control mice $(\mathrm{p}<0.05$, Student's t-test, $\mathrm{t}=-2.32 ;$ Fig. 4). Interestingly, the mGlula receptors in AZT+LAC group showed a trend to increase (although not statistical significant) in respect to AZT animals and their expression did not differ from that found in the Control group. Therefore, LAC treatment appeared to counteract the AZT-induced reduction of mGlula receptor expression. This phenomenon, although less evident, was also observed for mGlu5 receptor expression: the AZT group showed reduced receptor expression compared to Control group $(\mathrm{p}<0.05$, Student's t-test, $\mathrm{t}=-3.17$ ), while the AZT+LAC group showed a trend to increase. For what concerns the mGlu2/3 receptor no differences between the four experimental groups were found.

In Fig. 5 protein expression relative to ionotropic receptors is shown. The analysis by Student's t-test confirmed that AZT prenatal treatment yielded a significant reduction of Glul subunit of AMPA receptor expression in respect to Control mice $(\mathrm{p}<0.05$, Student's t-test, $\mathrm{t}=-3,43)$. Notably, the Glul subunit in AZT+LAC group showed a significant increase $(p<0.05$, Student's t-test, $\mathrm{t}=-2.59)$ in comparison with AZT mice and did not differ from Controls suggesting that LAC treatment prevented the reduction of receptor expression due to AZT. As for the AMPA GluR2 and NMDA NR1 subunits, no differences between groups were found.

Increased levels of lipid peroxidation and oxidative stress caused by AZT are prevented by LAC treatment

Occurrence of free radical generation and oxidative stress was monitored at birth and at PND60. On PND0, we tested the levels of $15-\mathrm{F}_{2 \mathrm{t}}-\mathrm{IsoP}$, a reliable and sensitive marker of oxidative stress [52], suitable for oxidative stress evaluation in small size samples. Consistent with the oxidative stress hypothesis of AZT toxicity, 15$\mathrm{F}_{2 \mathrm{t}}$-IsoP levels in whole brain homogenates (Fig. 6A) showed a trend to increase in samples from AZT prenatally-treated pups, but not in those from LAC or LAC+AZT groups. Protein carbonyl levels, which are considered a measure of protein oxidation and an index of oxidative stress [53-55], were measured by OxyBlot 


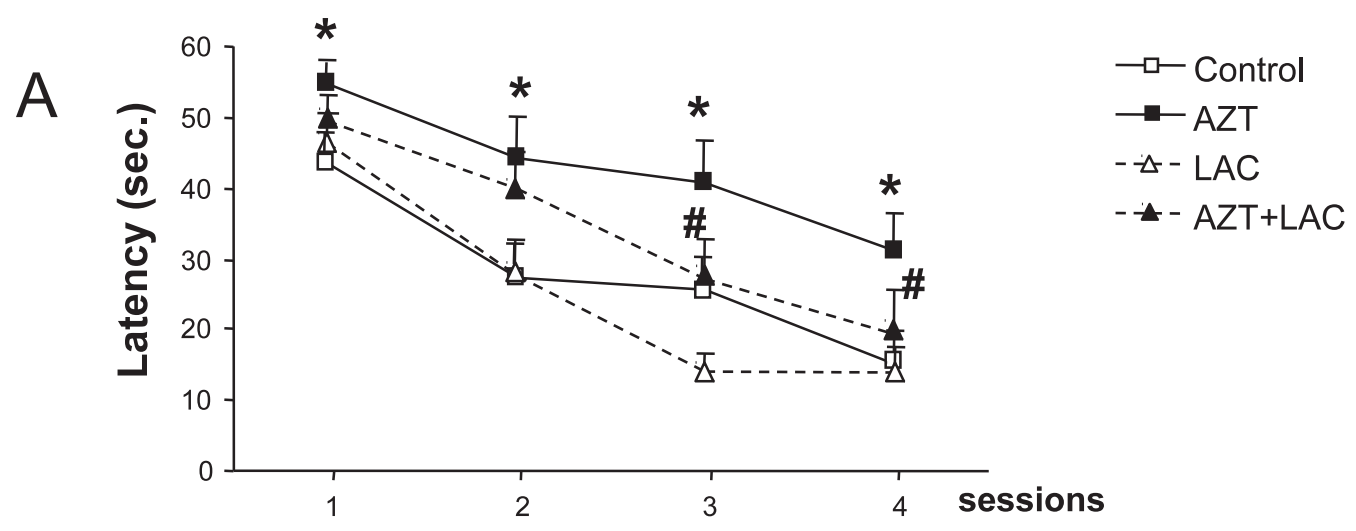

B
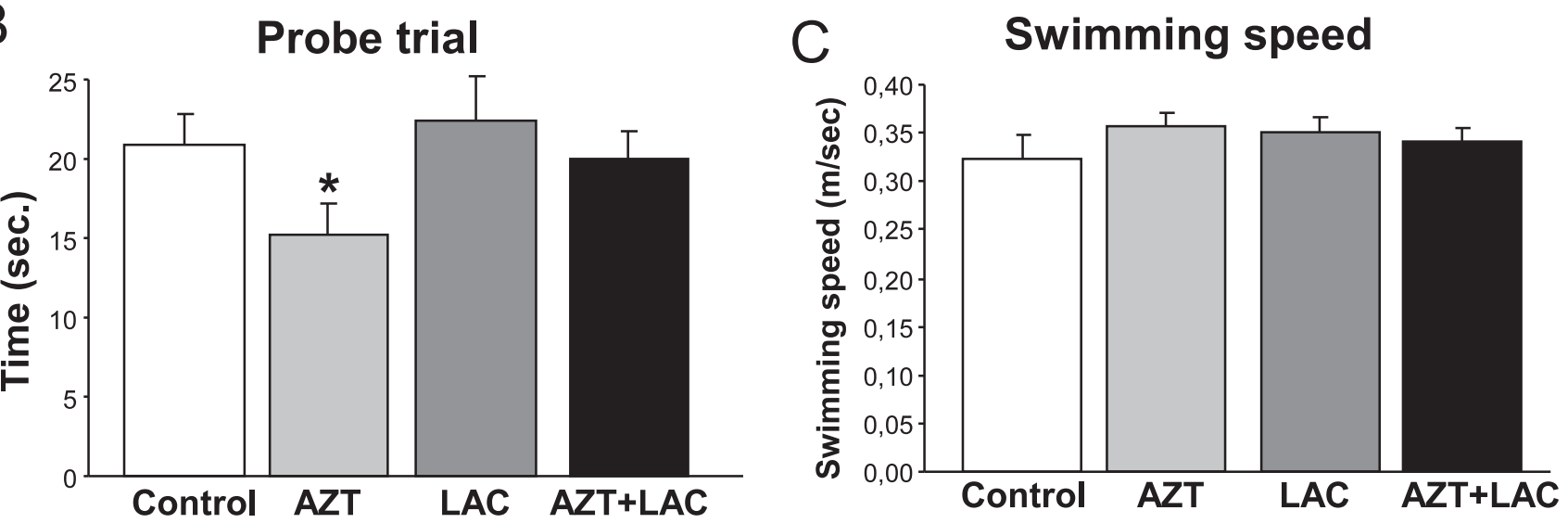

Figure 2. Effect of AZT and LAC treatments on spatial learning and memory assessed in the Morris Water Maze. A) Training sessions: Latencies to reach the hidden platform throughout the four sessions of the task. The higher latencies shown by AZT-treated mice in comparison to Control mice throughout the four sessions clearly indicate a learning impairment $\left({ }^{*} p<0.05\right.$, Fisher's LSD post-hoc performed on significant three-way ANOVA interaction), counteracted by LAC treatment, as the AZT+LAC group had latencies comparable to the Control group in the 3rd and 4th session, and significantly different from those of the AZT group (\# $p<0.05$ ). LAC treatment alone did not modify learning abilities. B) Probe trial: AZT-treated mice spent less time than Control mice in the quadrant where the platform was located during training $(* p<0.05$ AZT vs Control after $t$ test), indicating a deficit in memory recall. AZT+LAC mice did not differ from Controls. C) No treatment-induced difference was recorded in the swimming speed assessed in a trial with a visible platform. Values are expressed as means \pm S.E.M ( $n=7-8$ mice per group). doi:10.1371/journal.pone.0055753.g002

analysis of homogenates prepared from hippocampi of mice sacrificed at PND60, in parallel with glutamate receptor expression. In agreement with the tendency observed at PND0, a significant increase in carbonyls was found in the hippocampal homogenates from AZT prenatally-treated mice (45\% of Control, $\mathrm{p}<0.05$, Student's t-test, $\mathrm{t}=2,15$; Fig. 6). Significant decreases of protein carbonyls were detected in the hippocampus of mice treated with LAC and with the combination of AZT+LAC, as expected due to the antioxidant effect of LAC ( $p<0.05$, Student's $\mathrm{t}$-test, $\mathrm{t}=-3,45$ for LAC, $\mathrm{t}=-5,07$ for AZT+LAC; Fig. 6).

\section{Discussion}

In the past years, reports of clinical signs suggestive of mitochondrial dysfunction in non-infected children exposed to NRTIs have prompted studies addressing the issue of developmental toxicity of such drugs and, in particular, of AZT.

Occurrence of subclinical mitochondrial dysfunction has been consistently shown by either clinical and experimental studies in different tissues and organs, including the brain [11-14,36,56]. In particular, a recent study provided evidence that in utero exposure to the NRTI, AZT and Lamivudine, is associated with brain mitochondrial impairment, which progresses over time and might possibly end up in delayed neurobehavioral effects [32]. In laboratory rodents, developmental exposure to AZT produces both early and delayed behavioral changes in offspring including alteration in sensorimotor maturation, social/aggressive behavior, responses to environmental stressors and learning abilities [19-30]. Altogether, these data pointed to the potential risk of sub-clinical side effects of ARV therapy on the developing brain that may go undetected in clinical and epidemiological studies. Thus, current recommendations call for long-term clinical follow-up for any child with in utero exposure to ARV drugs [17] to monitor significant side effect of ARV drugs that may augment risk in children and adolescents born to HIV-1-positive women, who represent a vulnerable group as for psychiatric health [18,57-59].

The main results of the present preclinical study contribute to clarify this controversial issue, as they show that 1) transplacental exposure to AZT enhances oxidative stress and causes a consistent and permanent alteration of hippocampal glutammatergic neurotransmission functionally associated to a deficit in spatial learning and memory, 2) LAC administration from the beginning of 


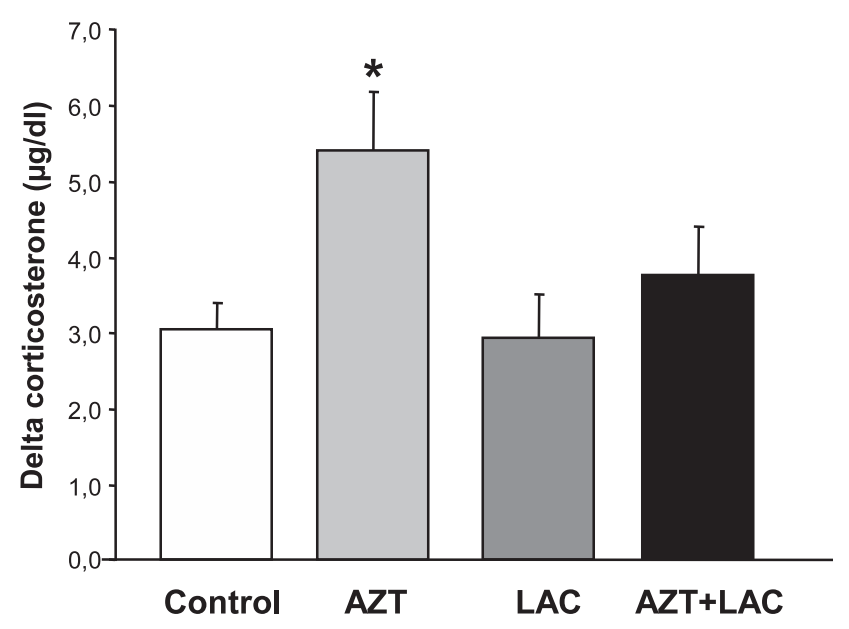

Figure 3. Effect of AZT and LAC treatments on plasma corticosterone secretion measured after 15-min restraint stress. In basal conditions, no significant differences were observed in plasma corticosterone levels between groups (see text for details), while following acute stress AZT-treated mice had markedly enhanced corticosterone release in comparison to Control mice ${ }^{*} p<0.05$ AZT vs Control, Student's $t$ test). LAC administration protected from AZTinduced increase of corticosterone. Corticosterone levels were calculated as delta between restraint stress values and basal values. Values are expressed as means \pm S.E.M. ( $n=7$ mice per group). doi:10.1371/journal.pone.0055753.g003

pregnancy prevents/ameliorates the adverse effects of AZT on both neurochemical and behavioral parameters.

In line with previous findings in rodent models, we show that transplacental AZT exposure has significant long-term effects on behavior of exposed offspring. In particular, AZT treatment has detrimental effects on performances in the water maze task, one of the most widely used tests to measure hippocampal-dependent spatial-based learning and memory in rodent models with high translational value with respect to humans [60]. We observed a marked deficit in acquisition and memory recall, as both acquisition of the platform location and retrieval of the acquired information in the probe trial were impaired in AZT-treated mice. Since swimming speed was not affected by AZT treatment, we can exclude motor impairment possibly associated with the wellknown effects of this drug on muscle tissue [61].

Different neurotransmitter systems have been implicated in the effects exerted by AZT and other ARV drugs on behavior but a correlation between specific neural mechanisms and the behavioral changes observed has not been attempted yet. Extensive evidence indicates that learning and memory components of spatial navigation in rodents rely on hippocampal synaptic plasticity [62-64] that is largely modulated by hippocampal mGlu $[65,66]$ and by AMPA receptors [67]. Our findings indicate that hippocampal glutamate neurotransmission is permanently affected by early AZT exposure and support a role of this important neurochemical pathway in the behavioral effects here reported.

The reduced expression of metabotropic group I and ionotropic Glul subunit of AMPA receptors in the hippocampus is well in agreement with the specific impairment of spatial learning and memory performances observed in AZT treated mice. Recent data strongly support a role for the different glutamate receptor subtypes in spatial cognition: administration to rats of mGluRl antagonists affects synaptic plasticity and impairs acquisition in the Morris water maze [68], while blockade of mGlu5 receptors interferes with long-term potentiation and has detrimental effects on spatial learning [69]. As well as for metabotropic group I receptors, there is ample evidence that the dynamic regulation of AMPA receptors - which mediate most of the fast excitatory synaptic transmission - can change synaptic function and regulate storage of information [70,71]. Based on our behavioral and neurochemical findings, we hypothesize that the lower expression of different subgroups of glutamate receptors in AZT mice results in reduced plasticity of hippocampal glutamatergic synapses and, as an ultimate consequence, in diminished capacity to encode relevant information during the spatial learning task.

Such effect could be further amplified by the enhanced corticosterone responsiveness to stress in AZT exposed mice. Our findings show that administration of AZT during pregnancy caused increased release of plasma corticosterone following acute restraint stress at adulthood. As water maze training induces release of high corticosterone levels shortly after completion of the task in mice [72], an abnormal physiological reaction to stress could interfere with both acquisition and consolidation of information in AZT mice. An inverse relationship between spatial learning and memory and elevated corticosterone levels has been widely demonstrated in rodents: exposure to mild stressor or moderate glucocorticoid levels facilitates spatial memory [73-76] while chronic stress or higher glucocorticoid levels exert detrimental effects on neuronal plasticity and spatial memory [77-79]. The increased corticosterone release after acute stress observed in AZT treated mice deserves further consideration, as it is suggestive of altered HPA axis response caused by early AZT exposure. A recent study indicates that chronic AZT is able to increase corticosterone release in adult rats possibly by a central action [80]. In a developmental perspective, AZT treatment could interfere with the physiological setting of HPA axis activity, thus reducing the capability to respond adaptively to environmental challenges. Previous studies from our laboratories indicate that mice exposed to AZT during development present abnormal reaction to novelty, and that pre- and/or postnatally AZT exposed adult male mice show maladaptive intraspecific social/aggressive behavior depending on the length of exposure [23,24].

Overall, our findings confirm the behavioral effects of transplacental AZT in rodent models. More importantly, they point for the first time to a specific and permanent action of this drug on glutamate neurotransmission. We propose that such effect is linked to the well-known mitochondrial toxicity of AZT [11,14,31,32,34,81-83]. NRTI-induced alterations in mitochondrial structure and function result from interference with various mechanisms involved in the normal maintenance of mitochondrial function. In particular, it has been suggested that AZT directly impairs the electron transport chain (ETC) thus increasing production of reactive oxygen species (ROS) and oxidative stress, which will eventually lead to a loss of the mtDNA integrity [84]. Our data confirm that transplacental exposure to AZT induces oxidative stress in the fetal brain and determines long-term effects on the oxidative status of brain tissue as two different oxidative stress markers, $15-\mathrm{F}_{2 \mathrm{t}}$-isoP and protein carbonyl levels at birth and at adulthood, respectively, were enhanced in AZT-treated offspring.

$\mathrm{F}_{2^{-}}$Isoprostanes are lipid peroxidation products; they are among the most sensitive in vivo biomarkers of oxidative stress and are the marker of choice for the evaluation of oxidative damage in small size samples such as newborn mouse brain [52]. Similarly, immunodetection of carbonyl groups provides a measure of oxidation status of proteins, and in turn, of oxidant injury. The increased levels of $15-\mathrm{F}_{2 \mathrm{t}}$-isoP and protein oxidation are indicative of increased levels of ROS, likely deriving from AZT-dependent 
$142 \mathrm{KDa}$ -

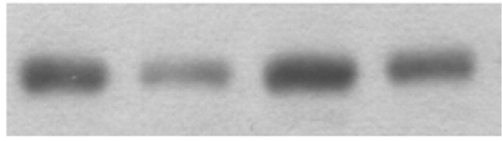

$45 \mathrm{KDa}-$

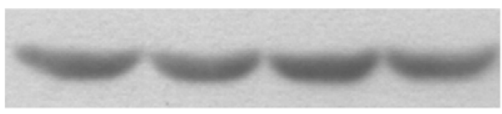

mGluR1a

$\beta$-actin

$130 \mathrm{KDa}-$

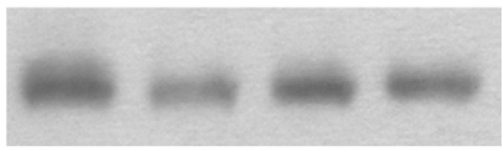

$45 \mathrm{KDa}-$

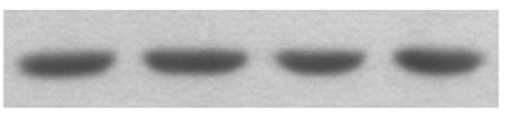

mGluR5

$\beta$-actin

$206 \mathrm{KDa}$ -

$100 \mathrm{KDa}-$

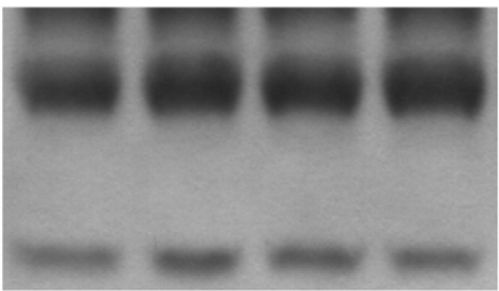

mGluR2/3

(dimer)

mGluR2/3

(monomer)

$45 \mathrm{KDa}-$

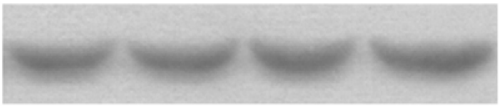

\section{$\beta$-actin}

B mGluR1a

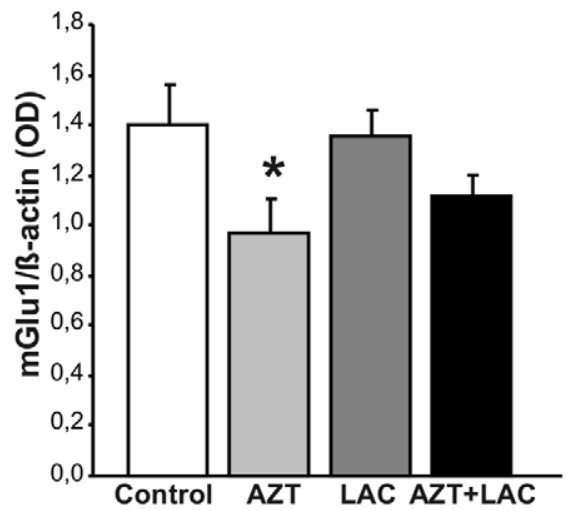

mGluR5

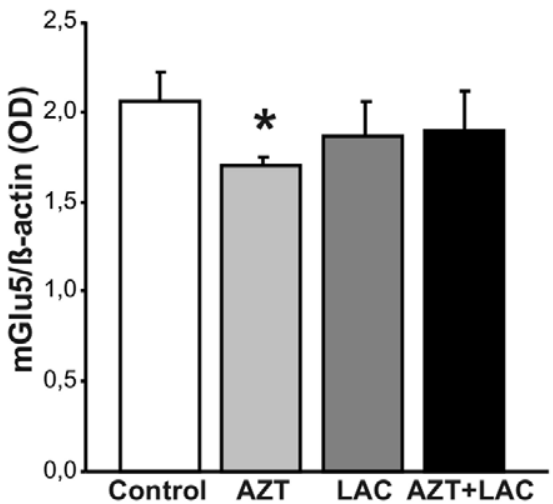

mGluR2/3

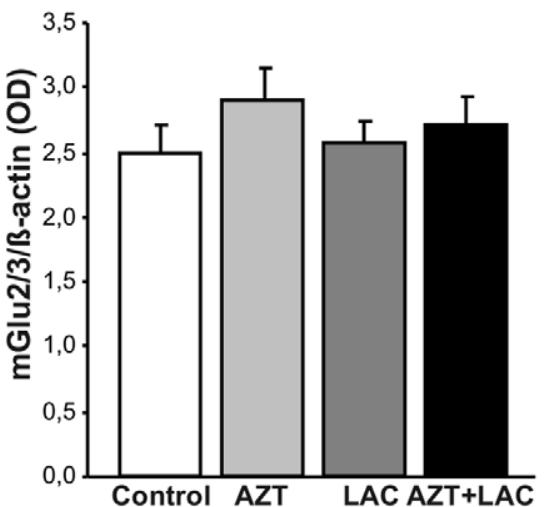

Figure 4. Effect of AZT and LAC treatments on hippocampal mGlu receptors expression. (A) Representatives of immunoblots with mGlu1a and mGlu5 receptor antibodies showed a $142 \mathrm{kDa}$ and $130 \mathrm{kDa}$ bands, corresponding to receptor monomers, respectively. Blots with antibodies recognize an epitope common to mGlu2 receptors monomer(s) (100 kDa) and mGlu3 receptors dimers (206 kDa). (B) Results are expressed as the ratio of the optical density (OD) of the mGluR1a, mGluR5 or mGlu2/3 band and the $\beta$-actin band. The AZT prenatal treatment caused a significant reduction of mGlu1a and mGlu5 receptors expression in respect to Control mice $(* p<0.05$, Student's t-test) counteracted by LAC treatment as AZT+LAC mice differ from Control. No differences between groups were found in the mGluR2/3 (summary of OD monomers and dimers). Values are expressed as means \pm S.E.M. ( $n=6$ mice per group).

doi:10.1371/journal.pone.0055753.g004

mitochondrial impairment, as described in several previous studies [5-8].

The evidence of early oxidative stress in AZT exposed offspring allows us to advance a mechanistic explanation for the endocrine and neurobehavioral effects here reported. Impairment of mitochondrial function and production of increased levels of ROS may reduce the capacity of the cell to generate ATP, and induce excess glutamate release at the synapse and, eventually, excitotoxicity [37]. In turn, an excess of glutamate release in the early stage of life results in overstimulation of glutamatergic receptors that can be possibly permanently modified in their expression and functionality. Besides, it should be considered that a significant portion of the control of HPA axis activity is mediated by glutamate [85-88] thus enhanced glutamate release during 
A

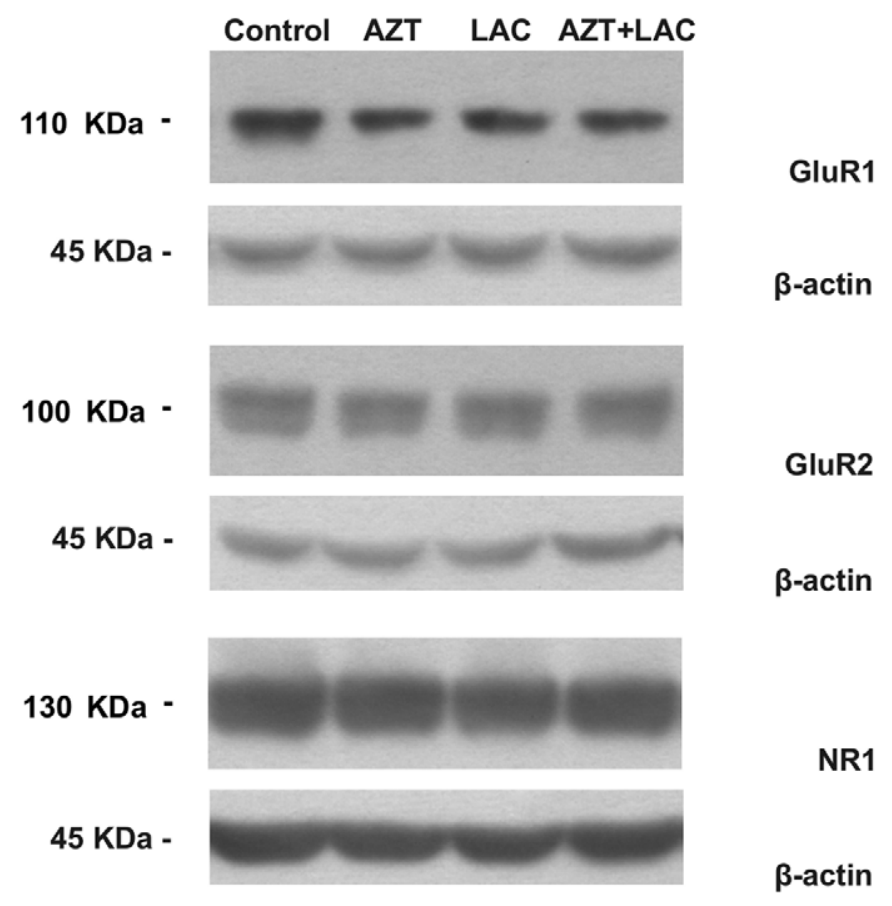

B AMPA Subunit GluR1

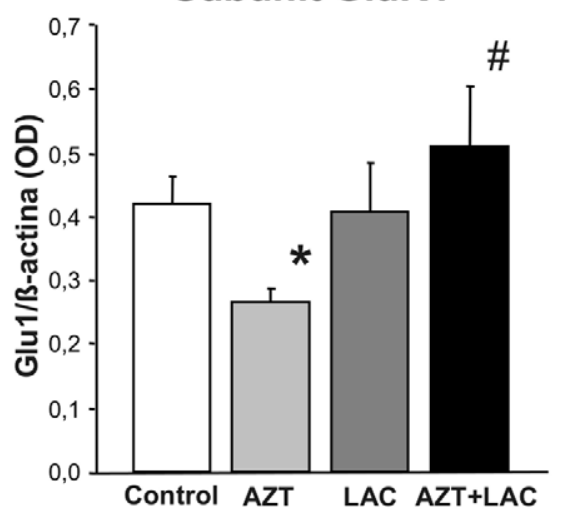

AMPA Subunit GluR2

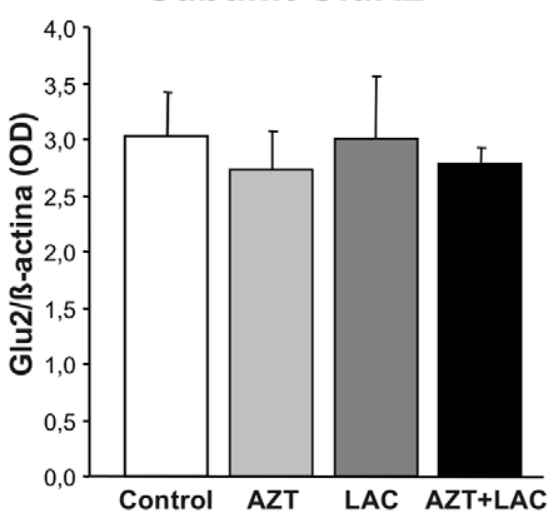

NMDA Subunit NR1

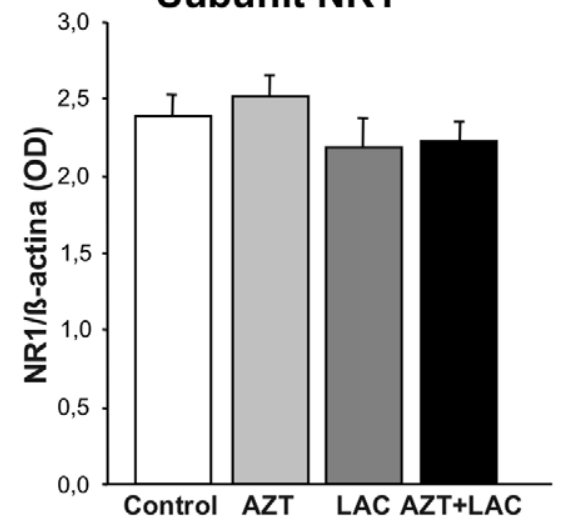

Figure 5. Effect of AZT and LAC treatments on hippocampal AMPA and NMDA receptors expression. (A) Representatives of immunoblots with GluR1 and GluR2 receptor antibodies showed a $110 \mathrm{kDa}$ and $100 \mathrm{kDa}$ bands corresponding to AMPA receptor subunits, respectively. Blot with NR1 receptor antibody showed a $130 \mathrm{kDa}$ band, corresponding to NMDA receptor subunit. (B) Results are expressed as the ratio of the optical density (OD) of the GluR1, GluR2 and NR1 band and the $\beta$-actin band. AZT prenatal treatment caused a significant reduction of the GluR1 subunit of AMPA receptors expression in respect to Control mice $(* p<0.05$ AZT vs Control, Student's t-test) that was fully prevented by LAC treatment: in AZT+LAC mice the Glu1 subunit was increased in respect to AZT mice (\# $p<0.05$ vs AZT, Student's t-test) and did not differ from Controls. Expression of the GluR2 subunit of AMPA and NR1 subunit of NMDA receptors was not affected by either treatment. Values are expressed as means \pm S.E.M. ( $n=6$ mice per group).

doi:10.1371/journal.pone.0055753.g005

early development could result in lifelong alteration of HPA axis responsiveness. The link between AZT-induced oxidative stress in the fetal stage and the long-term consequences on neurobehavioral functions at the adult stage is strongly supported by the protective effect exerted by LAC. Indeed, we show that most of the alterations induced by AZT are prevented or reduced by administration of LAC from the beginning of pregnancy.

Several lines of evidence indicate that administration of antioxidant agents, including vitamin $\mathrm{C}, \mathrm{E}$ and coenzyme Q10 prevents or alleviates oxidative stress and symptoms of AZTinduced myopathy in both rats and humans (see 61 for a review).
More relevant to our study, LAC is known to decrease oxidative stress by 1) exerting a protective effect on mitochondrial structure and function, making the ETC less prone for electron leak and superoxide production, and promoting mitochondrial biogenesis, as indicated by increased mitochondrial size and number [89]; 2) stimulating the endogenous cellular antioxidant defense mechanisms. These effects possibly rely on the ability of LAC to act as a donor of acetyl groups. In a recent work, a proteomic survey of protein acetylation identified that $20 \%$ of mitochondrial proteins presented with acetylation sites and these proteins included those involved in the tricarboxylic acid cycle, fatty acid $\beta$-oxidation, 
A

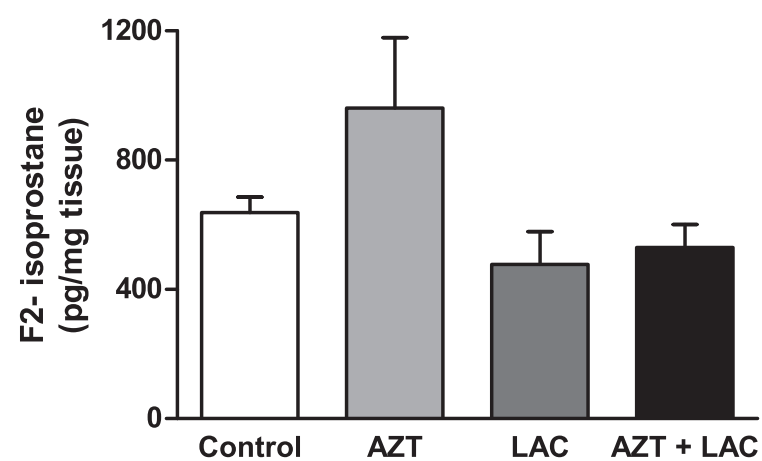

B

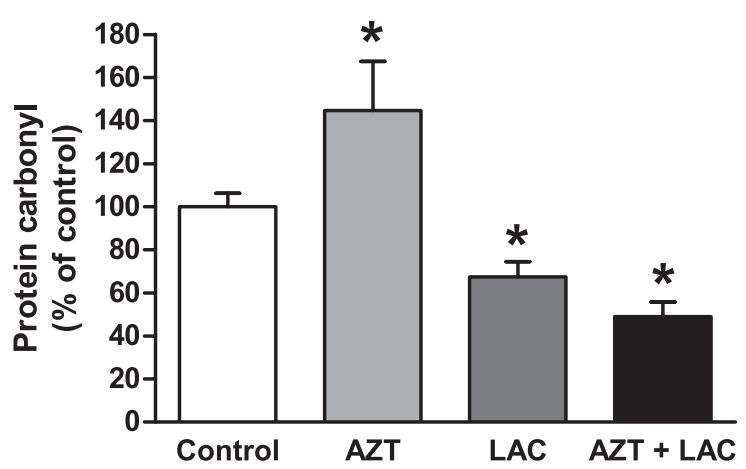

Figure 6. Effect of AZT and LAC treatments on brain oxidative stress in newborn and adult mice. (A) Levels of F2-Isoprostane, as marker of lipid peroxidation and oxidative stress, in brain homogenates from newborn mice. F2t-Isop levels in whole brain homogenates showed a trend to increase in samples from AZT prenatally-treated pups, but not in those from LAC or AZT+LAC groups. (B) Protein carbonyl content (Oxyblot) of hippocampal homogenates. The AZT prenatal treatment caused a significant increase of the protein carbonyl content in respect to Control mice. Both LAC and AZT+LAC groups showed a significant decrease of carbonyls in respect to Control mice indicating an antioxidant effect of the LAC treatment. ( ${ }^{*} p<0.05$ vs Control, Student's t-test). Values are expressed as means \pm S.E.M. ( $n=6-8$ mice per group).

doi:10.1371/journal.pone.0055753.g006

amino acid and carbohydrate metabolism, membrane transport, and ETC [90]. These data clearly show that acetylation can control the activity of mitochondrial enzymes and, since acetyl$\mathrm{CoA}$ is the acetylation donor for all known acetyltransferases, the concentration of mitochondrial acetyl-CoA could be a limiting factor in the acetylation reaction. By increasing the acetyl-CoA content, supplemented LAC should increase the acetylation status of mitochondrial proteins thus improving mitochondrial function and integrity. Interestingly, low levels of circulating LAC have been found in HIV-1 patients experiencing a clinically manifest peripheral neuropathy while staying on AZT and other nucleoside analogue treatment [91], and in patients with AZT-induced mtDNA depletion [92]. Hence, LAC deficiency could play a role in neurotoxic effects of these drugs. AZT treatment reduces carnitine levels in blood and tissues [5,6] and LAC treatment could mediate an improvement of mitochondrial dysfunction in a straightforward manner, namely, by replenishing carnitine levels.

Other clinical studies have shown that treatment with LAC improved NRTI-induced polyneuropathy symptoms in HIV-1positive patients, including electrophysiological variables relating to motor conduction velocity [93]. In a morphological study in HIV-1 patients with distal symmetrical polyneuropathy, regeneration of all fiber types and in particular of small sensory fibers in the dermis, epidermis and sweat glands was observed after oral LAC treatment [94]. All this considered, LAC can be viewed as a pleiotropic molecule metabolically active, with neuromodulatory, neurotrophic, cytoprotective, and antioxidant activity in brain.

The use of ARV drugs to prevent mother-to-child transmission of HIV-1 infection is one of the most successful achievements in HIV-1 prevention and, based on several clinical and epidemiological studies, benefits of this therapy appear to outweigh its adverse side effects in exposed infant/children [2,95]. However, there is still considerable uncertainty on the prevalence and severity of mitochondrial toxicity associated to ARV treatment in pregnancy [96]. In this framework, research on therapeutic intervention effective in reducing side effect risks of this life-saving regimen should be implemented. The present preclinical findings, besides providing a mechanistic hypothesis for the neurobehavioral effects of AZT, strongly suggest that preventive administration of LAC already shown to improve NRTI-induced polyneuropathy in HIV-1-positive patients [45-48] might also be effective in reducing the neurological side-effects of ARV therapy in fetus/ newborn.

It is known that an excessive production of pro-inflammatory cytokines and free radicals might occur during HIV infection. Because pro-inflammatory cytokines and free radicals can travel through placenta to the fetus, they could contribute to increase the fetal oxidative stress induced by NRTI drugs. Nonetheless, our results highlight the importance of counteracting the neurotoxic effects of NRTIs in terms of rescue of neuronal function based on the maintenance of mitochondrial activity. Since LAC treatment has generally shown a good profile of safety and tolerability, our study strongly supports the rationale for the development of clinical trials aimed at investigating the efficacy of the administration of LAC to HIV-1 infected pregnant women treated with NRTIs to counteract potential adverse consequences on their children.

\section{Acknowledgments}

The authors wish to express their gratitude to Dr. Assia Catalani for kindly advice relating to this research and to Dr. Flavia Chiarotti for her statistical support.

\section{Author Contributions}

Conceived and designed the experiments: GG PG AVP. Performed the experiments: ARZ GG AVP AT MAAG CG AG GP. Analyzed the data: ARZ GG AVP GSA LM RN GC PC. Wrote the paper: GC PC LM RN.

\section{References}

1. Mofenson LM (2003) Advances in the prevention of vertical transmission of human immunodeficiency virus. Semin Pediatr Infect Dis 14: 295-308.

2. Thorne C, Newell ML (2007) Safety of agents used to prevent mother-to-child transmission of HIV: is there any cause for concern? Drug Saf 30: 203-213.

3. Cooper ER, Charurat M, Mofenson L, Hanson IC, Pitt J, et al. (2002) Combination antiretroviral strategies for the treatment of pregnant HIV-1infected women and prevention of perinatal HIV-1 transmission. J Acquir Immune Defic Syndr 29: 484-494.

4. European Collaborative Study (2003) Exposure to antiretroviral therapy in utero or early life: the health of uninfected children born to HIV-infected women. $\mathrm{J}$ Acquir Immune Defic Syndr 32: 380-387.

5. Kakuda TN (2000) Pharmacology of nucleoside and nucleotide reverse transcriptase inhibitor-induced mitochondrial toxicity. Clin Ther 22: 685-708.

6. Dagan T, Sable C, Bray J, Gerschenson M (2002) Mitochondrial dysfunction and antiretroviral nucleoside analog toxicities: what is the evidence? Mitochondrion 1: 397-412. 
7. Lewis W, Day BJ, Copeland WC (2003) Mitochondrial toxicity of NRTI antiviral drugs: an integrated cellular perspective. Nat Rev Drug Discov 2: 812 822.

8. Kohler JJ, Lewis W (2007) A brief overview of mechanisms of mitochondrial toxicity from NRTIs. Environ Mol Mutagen 48: 166-172.

9. Walker VE, Poirier MC (2007) Special issue on health risks of perinatal exposure to nucleoside reverse transcriptase inhibitors. Environ Mol Mutagen 48: 159165.

10. Torres SM, Walker DM, Carter MM, Cook DL Jr, McCash CL, et al. (2007) Mutagenicity of zidovudine, lamivudine, and abacavir following in vitro exposure of human lymphoblastoid cells or in utero exposure of CD-1 mice to single agents or drug combinations. Environ Mol Mutagen 48: 224-238.

11. Poirier MC, Divi RL, Al-Harthi L, Olivero OA, Nguyen V, et al. (2003) Longterm mitochondrial toxicity in HIV-uninfected infants born to HIV-infected mothers. J Acquir Immune Defic Syndr 33: 175-183

12. Divi RL, Walker VE, Wade NA, Nagashima K, Seilkop SK, et al. (2004) Mitochondrial damage and DNA depletion in cord blood and umbilical cord from infants exposed in utero to Combivir. AIDS 18: 1013-1021.

13. Shiramizu B, Shikuma KM, Kamemoto L, Gerschenson M, Erdem G, et al. (2003) Placenta and cord blood mitochondrial DNA toxicity in HIV-infected women receiving nucleoside reverse transcriptase inhibitors during pregnancy. J Acquir Immune Defic Syndr 32: 370-374.

14. Barret B, Tardieu M, Rustin P, Lacroix C, Chabrol B, et al. (2003) Persistent mitochondrial dysfunction in HIV-1-exposed but uninfected infants: clinical screening in a large prospective cohort. AIDS 17: 1769-1785.

15. Tardieu M, Brunelle F, Raybaud C, Ball W, Barret B, et al. (2005) Cerebral MR imaging in uninfected children born to HIV-seropositive mothers and perinatally exposed to zidovudine. AJNR Am J Neuroradiol 26: 695-701.

16. Landreau-Mascaro A, Barret B, Mayaux MJ, Tardieu M, Blanche S (2002) Risk of early febrile seizure with perinatal exposure to nucleoside analogues. Lancet 359: 583-584.

17. Panel on Treatment of HIV-Infected Pregnant Women and Prevention of Perinatal Transmission (2011) Recommendations for Use of Antiretroviral Drugs in Pregnant HIV-1-Infected Women for Maternal Health and Interventions to Reduce Perinatal HIV Transmission in the United States. MMWR Recomm Rep 51: 1-38.

18. Mellins CA, Smith R, O'Driscoll P, Magder LS, Brouwers P, et al. (2003) High rates of behavioral problems in perinatally HIV-infected children are not linked to HIV disease. Pediatrics 111: 384-393.

19. Calamandrei G, Venerosi A, Branchi I, Alleva E (1999) Effects of prenatal zidovudine treatment on learning and memory capacities of preweanling and young adult mice. Neurotoxicology 20: 17-25.

20. Calamandrei G, Venerosi A, Branchi I, Chiarotti F, Verdina A, et al. (1999) Effects of prenatal AZT on mouse neurobehavioral development and passive avoidance learning. Neurotoxicol Teratol 21: 29-40.

21. Calamandrei G, Venerosi A, Valanzano A, Alleva E (2000) Effects of prenatal AZT $+3 \mathrm{TC}$ treatment on open field behavior and responsiveness to scopolamine in adult mice. Pharmacol Biochem Behav 67: 511-517.

22. Calamandrei G, Rufini O, Valanzano A, Puopolo M (2002) Long-term effects of developmental exposure to zidovudine on exploratory behavior and novelty discrimination in CD-1 mice. Neurotoxicol Teratol 24: 529-540.

23. Rondinini C, Venerosi A, Branchi I, Calamandrei G, Alleva E (1999) Long-term effects of prenatal 3'-azido-3'-deoxythymidine (AZT) exposure on intermale aggressive behaviour of mice. Psychopharmacology (Berl) 145: 317-323.

24. Venerosi A, Cirulli F, Lil'p IG, Fiore M, Calamandrei G, et al. (2000) Prolonged perinatal exposure to AZT affects aggressive behaviour of adult CD-1 mice. Psychopharmacology (Berl) 150: 404-411.

25. Venerosi A, Valanzano A, Alleva E, Calamandrei G (2001) Prenatal exposure to anti-HIV drugs: neurobehavioral effects of zidovudine (AZT)+lamivudine (3TC) treatment in mice. Teratology 63: 26-37.

26. Venerosi A, Cirulli F, Capone F, Alleva E (2003) Prolonged perinatal AZT administration and early maternal separation: effects on social and emotional behaviour of periadolescent mice. Pharmacol Biochem Behav 74: 671-681.

27. Venerosi A, Valanzano A, Puopolo M, Calamandrei G (2005) Neurobehavioral effects of prenatal exposure to AZT: a preliminary investigation with the D1 receptor agonist SKF 38393 in mice. Neurotoxicol Teratol 27: 169-173.

28. Busidan Y, Dow-Edwards DL (1999) Neurobehavioral effects of perinatal AZT exposure in Sprague-Dawley weaning rats. Pharmacol Biochem Behav 64: 479485.

29. Busidan Y, Dow-Edwards DL (1999) Neurobehavioral effects of perinatal AZT exposure in Sprague-Dawley adult rats. Neurotoxicol Teratol 21: 359-363.

30. Melnick SM, Weedon J, Dow-Edwards DL (2005) Perinatal AZT exposure alters the acoustic and tactile startle response to 8-OH-DPAT and apomorphine in adult rats. Neurotoxicol Teratol 27: 599-608.

31. Chan SS, Santos JH, Meyer JN, Mandavilli BS, Cook DL Jr, et al. (2007) Mitochondrial toxicity in hearts of CD-1 mice following perinatal exposure to AZT, 3TC, or AZT/3TC in combination. Environ Mol Mutagen 48: 190-200.

32. Divi RL, Einem TL, Fletcher SL, Shockley ME, Kuo MM, et al. (2010) Progressive mitochondrial compromise in brains and livers of primates exposed in utero to nucleoside reverse transcriptase inhibitors (NRTIs). Toxicol Sci 118: 191-201.

33. Poirier MC, Patterson TA, Slikker W Jr, Olivero OA (1999) Incorporation of 3'azido-3'-deoxythymidine (AZT) into fetal DNA and fetal tissue distribution of drug after infusion of pregnant late-term rhesus macaques with a humanequivalent AZT dose. J Acquir Immune Defic Syndr 22: 477-483.

34. Walker DM, Poirier MC, Campen MJ, Cook DL Jr, Divi RL, et al. (2004) Persistence of mitochondrial toxicity in hearts of female B6C3F1 mice exposed in utero to 3 '-azido-3'-deoxythymidine. Cardiovasc Toxicol 4: 133-153.

35. Gerschenson M, Erhart SW, Paik CY, St Claire MC, Nagashima K, et al. (2000) Fetal mitochondrial heart and skeletal muscle damage in Erythrocebus patas monkeys exposed in utero to 3 '-azido-3'-deoxythymidine. AIDS Res Hum Retroviruses 16: 635-644.

36. Torres SM, March TH, Carter MM, McCash CL, Seilkop SK, et al. (2010) In utero exposure of female CD-1 Mice to AZT and/or 3TC: I. Persistence of microscopic lesions in cardiac tissue. Cardiovasc Toxicol 10: 37-50.

37. Nicholls DG, Budd SL (2000) Mitochondria and neuronal survival. Physiol Rev 80: 315-360.

38. Bortolotto ZA, Fitzjohn SM, Collingridge GL (1999) Roles of metabotropic glutamate receptors in LTP and LTD in the hippocampus. Curr Opin Neurobiol 9: 299-304

39. Cinque C, Zuena AR, Casolini P, Ngomba RT, Melchiorri D, et al. (2003) Reduced activity of hippocampal group-I metabotropic glutamate receptors in learning-prone rats. Neuroscience 122: 277-284.

40. Bergink V, van Megen HJ, Westenberg HG (2004) Glutamate and anxiety. Eur Neuropsychopharmacol 14: 175-183.

41. Brann DW, Mahesh VB (1994) Excitatory amino acids: function and significance in reproduction and neuroendocrine regulation. Front Neuroendocrinol 15: 3-49.

42. Yokoi N, Fukata M, Fukata Y (2012) Synaptic plasticity regulated by proteinprotein interactions and posttranslational modifications. Int Rev Cell Mol Biol 297: 1-43.

43. Ferraguti F, Crepaldi L, Nicoletti F (2008) Metabotropic glutamate 1 receptor: current concepts and perspectives. Pharmacol Rev 60: 536-581.

44. Jones LL, McDonald DA, Borum PR (2010) Acylcarnitines: role in brain. Prog Lipid Res 49: 61-75.

45. Scarpini E, Sacilotto G, Baron P, Cusini M, Scarlato G (1997) Effect of acetyl-Lcarnitine in the treatment of painful peripheral neuropathies in HIV+ patients. J Peripher Nerv Syst 2: 250-252.

46. Herzmann C, Johnson MA, Youle M (2005) Long-term effect of acetyl-Lcarnitine for antiretroviral toxic neuropathy. HIV Clin Trials 6: 344-350.

47. Youle M, Osio M (2007) A double-blind, parallel-group, placebo-controlled, multicentre study of acetyl L-carnitine in the symptomatic treatment of antiretroviral toxic neuropathy in patients with HIV-1 infection. HIV Med 8: 241-250.

48. Valcour V, Yeh TM, Bartt R, Clifford D, Gerschenson M, et al. (2009) Acetyl-lcarnitine and nucleoside reverse transcriptase inhibitor-associated neuropathy in HIV infection. HIV Med 10: 103-110.

49. Minghetti L, Greco A, Cardone F, Puopolo M, Ladogana A, et al. (2000) Increased brain synthesis of prostaglandin E2 and F2-isoprostane in human and experimental transmissible spongiform encephalopathies. J Neuropathol Exp Neurol 59: 866-871.

50. Frick KM, Burlingame LA, Arters JA, Berger-Sweeney J (2000) Reference memory, anxiety and estrous cyclicity in C57BL/6NIA mice are affected by age and sex. Neuroscience 95: 293-307.

51. Chappuy H, Treluyer JM, Jullien V, Dimet J, Rey E, et al. (2004) Maternal-fetal transfer and amniotic fluid accumulation of nucleoside analogue reverse transcriptase inhibitors in human immunodeficiency virus-infected pregnant women. Antimicrob Agents Chemother 48: 4332-4336.

52. Greco A, Minghetti L (2004) Isoprostanes as biomarkers and mediators of oxidative injury in infant and adult central nervous system diseases. Curr Neurovasc Res 1: 341-354

53. Oliver CN, Starke-Reed PE, Stadtman ER, Liu GJ, Carney JM, et al. (1990) Oxidative damage to brain proteins, loss of glutamine synthetase activity, and production of free radicals during ischemia/reperfusion-induced injury to gerbil brain. Proc Natl Acad Sci U S A 87: 5144-5147.

54. Smith CD, Carney JM, Starke-Reed PE, Oliver CN, Stadtman ER, et al. (1991) Excess brain protein oxidation and enzyme dysfunction in normal aging and in Alzheimer disease. Proc Natl Acad Sci U S A 88: 10540-10543.

55. Stadtman ER, Levine RL (2003) Free radical-mediated oxidation of free amino acids and amino acid residues in proteins. Amino Acids 25: 207-218.

56. Brogly SB, DiMauro S, Van Dyke RB, Williams PL, Naini A, et al. (2011) Short communication: transplacental nucleoside analogue exposure and mitochondrial parameters in HIV-uninfected children. AIDS Res Hum Retroviruses 27: 777 783.

57. Chase C, Ware J, Hittelman J, Blasini I, Smith R, et al. (2000) Early cognitive and motor development among infants born to women infected with human immunodeficiency virus. Women and Infants Transmission Study Group. Pediatrics 106: E25.

58. Esposito S, Musetti L, Musetti MC, Tornaghi R, Corbella S, et al. (1999) Behavioral and psychological disorders in uninfected children aged 6 to 11 years born to human immunodeficiency virus-seropositive mothers. J Dev Behav Pediatr 20: 411-417.

59. Mellins CA, Brackis-Cott E, Dolezal C, Meyer-Bahlburg HF (2005) Behavioral risk in early adolescents with HIV+ mothers. J Adolesc Health 36: 342-351.

60. Nedelska Z, Andel R, Laczo J, Vlcek K, Horinek D, et al. (2012) Spatial navigation impairment is proportional to right hippocampal volume. Proc Natl Acad Sci U S A 109: 2590-2594. 
61. Scruggs ER, Dirks Naylor AJ (2008) Mechanisms of zidovudine-induced mitochondrial toxicity and myopathy. Pharmacology 82 : 83-88.

62. Shapiro ML, Eichenbaum H (1999) Hippocampus as a memory map: synaptic plasticity and memory encoding by hippocampal neurons. Hippocampus 9: 365-384.

63. Martin SJ, Morris RG (2002) New life in an old idea: the synaptic plasticity and memory hypothesis revisited. Hippocampus 12: 609-636.

64. Pittenger C, Kandel ER (2003) In search of general mechanisms for long-lasting plasticity: Aplysia and the hippocampus. Philos Trans R Soc Lond B Biol Sci 358: 757-763.

65. Balschun D, Manahan-Vaughan D, Wagner T, Behnisch T, Reymann KG, et al. (1999) A specific role for group I mGluRs in hippocampal LTP and hippocampus-dependent spatial learning. Learn Mem 6: 138-152.

66. Naie K, Manahan-Vaughan D (2004) Regulation by metabotropic glutamate receptor 5 of LTP in the dentate gyrus of freely moving rats: relevance for learning and memory formation. Cereb Cortex 14: 189-198.

67. Bannerman DM, Rawlins JN, Good MA (2006) The drugs don't work-or do they? Pharmacological and transgenic studies of the contribution of NMDA and GluR-A-containing AMPA receptors to hippocampal-dependent memory. Psychopharmacology (Berl) 188: 552-566.

68. Schroder UH, Muller T, Schreiber R, Stolle A, Zuschratter W, et al. (2008) The potent non-competitive mGlul receptor antagonist BAY 36-7620 differentially affects synaptic plasticity in area cornu ammonis 1 of rat hippocampal slices and impairs acquisition in the water maze task in mice. Neuroscience 157: 385-395.

69. Bikbaev A, Neyman S, Ngomba RT, Conn PJ, Nicoletti F, et al. (2008) MGluR5 mediates the interaction between late-LTP, network activity, and learning. PLoS One 3: e2155.

70. Rumpel S, LeDoux J, Zador A, Malinow R (2005) Postsynaptic receptor trafficking underlying a form of associative learning. Science 308: 83-88.

71. Kessels HW, Malinow R (2009) Synaptic AMPA receptor plasticity and behavior. Neuron 61: 340-350.

72. Harrison FE, Hosseini AH, McDonald MP (2009) Endogenous anxiety and stress responses in water maze and Barnes maze spatial memory tasks. Behav Brain Res 198: 247-251

73. Pugh CR, Tremblay D, Fleshner M, Rudy JW (1997) A selective role for corticosterone in contextual-fear conditioning. Behav Neurosci 111: 503-511.

74. Roozendaal B, McGaugh JL (1997) Glucocorticoid receptor agonist and antagonist administration into the basolateral but not central amygdala modulates memory storage. Neurobiol Learn Mem 67: 176-179.

75. Liu L, Tsuji M, Takeda H, Takada K, Matsumiya T (1999) Adrenocortical suppression blocks the enhancement of memory storage produced by exposure to psychological stress in rats. Brain Res 821: 134-140.

76. Akirav I, Kozenicky M, Tal D, Sandi C, Venero C, et al. (2004) A facilitative role for corticosterone in the acquisition of a spatial task under moderate stress. Learn Mem 11: 188-195.

77. Luine V, Villegas M, Martinez C, McEwen BS (1994) Repeated stress causes reversible impairments of spatial memory performance. Brain Res 639: 167170 .

78. Diamond DM, Fleshner M, Ingersoll N, Rose GM (1996) Psychological stress impairs spatial working memory: relevance to electrophysiological studies of hippocampal function. Behav Neurosci 110: 661-672.

79. de Quervain DJ, Roozendaal B, McGaugh JL (1998) Stress and glucocorticoids impair retrieval of long-term spatial memory. Nature 394: 787-790.
80. Tortorella C, Guidolin D, Petrelli L, De TR, Milanesi O, et al. (2009) Prolonged zidovudine administration induces a moderate increase in the growth and steroidogenic capacity of the rat adrenal cortex. Int J Mol Med 23: 799-804.

81. Blanche S, Tardieu M, Rustin P, Slama A, Barret B, et al. (1999) Persistent mitochondrial dysfunction and perinatal exposure to antiretroviral nucleoside analogues. Lancet 354: 1084-1089.

82. Bishop JB, Witt KL, Tice RR, Wolfe GW (2004) Genetic damage detected in CD-1 mouse pups exposed perinatally to $3^{\prime}$-azido- $3^{\prime}$-deoxythymidine and dideoxyinosine via maternal dosing, nursing, and direct gavage. Environ $\mathrm{Mol}$ Mutagen 43: 3-9.

83. Divi RL, Leonard SL, Kuo MM, Nagashima K, Thamire C, et al. (2007) Transplacentally exposed human and monkey newborn infants show similar evidence of nucleoside reverse transcriptase inhibitor-induced mitochondrial toxicity. Environ Mol Mutagen 48: 201-209.

84. Yamaguchi T, Katoh I, Kurata S (2002) Azidothymidine causes functional and structural destruction of mitochondria, glutathione deficiency and HIV-1 promoter sensitization. Eur J Biochem 269: 2782-2788.

85. Herman JP, Mueller NK, Figueiredo H (2004) Role of GABA and glutamate circuitry in hypothalamo-pituitary-adrenocortical stress integration. Ann N Y Acad Sci 1018: 35-45.

86. Jezova D (2005) Control of ACTH secretion by excitatory amino acids: functional significance and clinical implications. Endocrine 28: 287-294.

87. Darlington DN, Miyamoto M, Keil LG, Dallman MF (1989) Paraventricular stimulation with glutamate elicits bradycardia and pituitary responses. Am J Physiol 256: R112-R119.

88. Makara GB, Stark E (1975) Effect of intraventricular glutamate on ACTH release. Neuroendocrinology 18: 213-216.

89. Petruzzella V, Baggetto LG, Penin F, Cafagna F, Ruggiero FM, et al. (1992) In vivo effect of acetyl-L-carnitine on succinate oxidation, adenine nucleotide pool and lipid composition of synaptic and non-synaptic mitochondria from cerebral hemispheres of senescent rats. Arch Gerontol Geriatr 14: 131-144.

90. Zhao S, Xu W, Jiang W, Yu W, Lin Y et al. (2010) Regulation of cellular metabolism by protein lysine acetylation. Science 327: 1000-1004.

91. Famularo G, Moretti S, Marcellini S, Trinchieri V, Tzantzoglou S, et al. (1997) Acetyl-carnitine deficiency in AIDS patients with neurotoxicity on treatment with antiretroviral nucleoside analogues. AIDS 11: 185-190.

92. Friese G, Froese K, Jaksch M, Kreuder J, Discher Th, et al. (2001) Acetylcarnitine deficiency and mitochondrial DNA-depletion in HIV patients treated with antiretroviral therapy. Antivi Ther 6 (suppl. 4): 44

93. Osio M, Muscia F, Zampini L, Nascimbene C, Mailland E, et al. (2006) Acetyl-lcarnitine in the treatment of painful antiretroviral toxic neuropathy in human immunodeficiency virus patients: an open label study. J Peripher Nerv Syst 11: $72-76$.

94. Hart AM, Wilson AD, Montovani C, Smith C, Johnson M, et al. (2004) Acetyl-lcarnitine: a pathogenesis based treatment for HIV-associated antiretroviral toxic neuropathy. AIDS 18: 1549-1560.

95. Watts DH (2006) Treating HIV during pregnancy: an update on safety issues. Drug Saf 29: 467-490.

96. Heidari S, Mofenson L, Cotton MF, Marlink R, Cahn P, et al, (2011) Antiretroviral drugs for preventing mother-to-child transmission of HIV: a review of potential effects on HIV-exposed but uninfected children. J Acquir Immune Defic Syndr 57: 290-296. 